\title{
OBSERVACIONES SOBRE LOS TITULARES EN LA PRENSA DEPORTIVA DIGITAL
}

\begin{abstract}
Resumen. El presente texto somete a un análisis léxico-pragmático una serie de titulares temáticos publicados en cuatro periódicos deportivos españoles en línea. Un medio digital polaco, supuestamente neutro, nos sirve de tertium comparationis. El trabajo intenta demostrar que existen notables diferencias en cuanto a la valoración positiva de los éxitos deportivos del Real Madrid y del Fútbol Club Barcelona entre los medios digitales madrileños y catalanes. El principal mecanismo discursivo que sirve para disminuir el efecto positivo de un éxito deportivo consiste en desviar la atención del lector con evaluaciones de los hechos y personajes de segundo plano a costa de lo verdaderamente factual. La interfaz polaca conserva, en la mayoría de los casos, una postura de neutralidad publicando titulares muy extensos, centrados únicamente en el aspecto informativo.
\end{abstract}

Palabras clave: prensa deportiva, prensa digital, titulares de prensa, discurso periodístico.

\section{Divisiones y funciones de los titulares de prensa}

En la tradición española abundan las definiciones y descripciones teóricas acerca de los titulares de prensa, publicadas tanto en los trabajos de investigación lingüística como en los manuales de redacción periodística llamados libros de estilo, lanzados por los grandes periódicos nacionales. Una de las primeras definiciones que se elaboró es la de Alarcos Llorach, quien califica los titulares como «letreros con que se indica o se da a conocer el contenido, objeto o destino de un escrito impreso en los periódicos (1977: 128)». Otras definiciones resaltan la función de acaparar la atención de consumidores de la prensa diaria: «la plasmación lingüística de la operación cognitiva de la atención, gracias a su colocación tipográfica en la noticia» (Jorques, 2000: 95-96). Los mencionados 'libros de estilo' (El País, 2014; El Mundo, 2002) apuntan a la función dominante de los titulares

\footnotetext{
* Katolicki Uniwersytet Lubelski Jana Pawła II.
} 
frente al cuerpo del texto: «los titulares constituyen el principal elemento de una información. Sirven para centrar la atención del lector e imponerle su contenido» (El País, 2014: 35; cfr. El Mundo, 2002: 39-40).

Las clasificaciones de los titulares que se encuentran en los trabajos dedicados al discurso periodístico atañen tanto a criterios formales como funcionales y discursivos. En primer lugar, la dimensión del texto que constituyen los titulares lleva naturalmente a su división rudimentaria en amplios y concentrados.

Añádase que varios rasgos que permiten divisiones de los titulares radican en el plano enunciativo-discursivo. Así, la intencionalidad de captar lo esencial del mensaje por parte del lector lleva a establecer la bipartición de los titulares en explícitos e implícitos. Por otro lado, la actitud del autor de la noticia, más o menos comprometida, puede desembocar en una distinción de los titulares en objetivos y comprometidos (véanse Alarcos Llorach, 1977: 137 y ss.; Oliva Marañón, 2011: 62-63).

Llama la atención la peculiar propuesta de Grijelmo (2001: 455, citado también por Gozalo Gómez, 2004: 659), por la que propone distinguir entre titulares-motor y titulares enunciativos. Los primeros se caracterizan por la rigurosidad informativa y aparecen en la prensa seria y oficial (por ejemplo en los grandes títulos nacionales) y los segundos son normalmente más concisos y se usan con frecuencia en los medios que mezclan la información seria con el entretenimiento:

Inundaciones en Sevilla (t. enunciativo)

Las inundaciones en Sevilla causan pérdidas por valor de 300 millones (t. motor)

Algunos autores indican que una parte de los titulares funcionan tan solo como meros señaladores enunciativos, privados de contenido informativo. Esta clase de titulares relacionada con la fuerza comunicativa del enunciado recibe la denominación de títulos-foco (Gozalo Gómez, 2004: 659).

Es obvio recordar que la principal función de los titulares de prensa se reduce a proporcionar un resumen del texto de la noticia, pues se trata casi siempre de un enunciado cuya extensión es muy reducida por las exigencias editoriales. Grijelmo apunta que sintetizar la noticia en un enunciado muy breve ha de responder a tres criterios: claridad, brevedad y atracción. Por otra parte, como recuerda el lingüista, los titulares de prensa no solo resumen el mensaje sino que también han de identificar y jerarquizar la noticia frente a otras, según el perfil social o ideológico de la prensa en que aparecen (2001: 456). 
Otra función primordial de los titulares consiste en despertar la curiosidad del lector por el contenido de la noticia (Alarcos Llorach, 1977: 128). Huelga explicar que esta característica cobra una importancia particular en la prensa digital, donde se emplean diversas estratagemas extralingüísticas a fin de incitar al lector a pinchar el enlace e ir al cuerpo del texto. Las dos funciones que hemos presentado de manera rudimentaria se relacionan con un hecho innegable: «constituyen las únicas secuencias leídas por gran parte de consumidores diarios. No en vano el titular es para Steel (1971: 15) la forma periodística por antonomasia» (Nadal Palazón, 2008: 177).

\section{Rasgos formales de los titulares}

En varias ocasiones, los textos de los titulares de prensa han de alcanzar una brevedad máxima, hecho que exige de los autores seleccionar los recursos lingüísticos a fin de conseguir el efecto informativo deseado. Pese a que, por diversos motivos, la relación entre la escasez de recursos formales y la alta densidad informativa del enunciado se transgrede con bastante frecuencia, los periodistas tienden a usar toda clase de acortamientos formales entre los que destaca la elipsis verbal. La presencia del verbo no parece ser necesaria para la comprensión del mensaje de tipo eslogan. Es más, en numerosos contextos la aparición de un verbo podría saturar en exceso la semántica del enunciado y producir un efecto estilístico distinto del que se desea alcanzar:

Costa quiere seguir y el Atlético que siga (elmundo.es; 01.05.14)

Costa quiere seguir y el Atlético quiere que siga (versión modificada)

A menudo, los autores chocan con la imposibilidad de restituir el actante responsable de los hechos relatados, sea porque a la hora de describir el suceso, este se desconocía o porque parecía tener poca relevancia comunicarlo a los lectores. Con este hecho se relaciona la alta frecuencia de omisiones argumentales en los titulares de prensa: elipsis del sujeto o del objeto de la oración.

La siguiente razón por la que no se expresan los participantes en el evento relatado es el deseo del autor del titular de conseguir una lectura objetiva, distanciarse de los hechos ocurridos o suavizar su posible efecto negativo: ¡Adiós a la copa! ¡Adiós a la liga!, etc. 
Vista la importancia del criterio como falta de espacio tipográfico, el uso de la metonimia es uno de los recursos potentes en los titulares de la prensa española:

Paseo del Madrid (elmundo.es; 30.04.14)

Varios recursos empleados en los titulares no solo se inscriben perfectamente en el tamaño reducido del titular sino que también se convierten en estratagemas discursivas que impactan al lector y canalizan su aprehensión del mensaje: nominalizaciones atípicas, frases hechas, a menudo de sentido figurado o metafórico, hasta diversos tropos retóricos que han de desembocar en valoraciones subjetivas del contenido del mensaje:

\section{La bestia era blanca}

‘Todos monos' (elmundo.es; 30.04.14)

Finalmente, parece conveniente mencionar la presencia en los titulares de diversos juegos de palabras. Todos los ejemplos que se citan a continuación aparecieron también en las portadas de las ediciones en papel respectivas, publicadas uno o dos días después de la fecha de su aparición en la interfaz digital:

Un tropiezo reLevante (marca.es; 04.05.14)

Marcó Asensio (as.com; 22.09.18)

¡BarVARidad! (sport.es; 23.09.18)

A este respecto, es interesante observar que Fuente González (1991: 161 y ss.) considera el aprovechamiento de la tipografía como uno de los recursos fundamentales de la creación de los titulares periodísticos, junto con la concisión, y el deseo de captar al receptor: «Una letra especial, un recuadro, unos titulares grandes, o por el contrario, la ausencia de título en una noticia, pueden, por ejemplo, aumentar o disminuir su efecto, según la voluntad del que haga la compaginación del periódico».

\section{Corpus y censo de datos}

Ante un objetivo muy especial, nos hemos servido, como referencia textual, de las versiones digitales de dos periódicos madrileños y visiblemente madridistas (As y Marca) y de dos periódicos catalanes, por cierto, barcelonistas antes que otra cosa (Mundo Deportivo y Sport). 
En calidad de tertium comparationis, hemos recurrido a la página sport.p1 ${ }^{1}$, medio digital polaco supuestamente neutral, aunque como bien es sabido la rivalidad entre el Real Madrid y el F. C. Barcelona divide al mundo entero y hasta los periodistas de la prensa deportiva polaca se declaran madridistas o barcelonistas.

Con vistas a comparar las funciones de los titulares de la prensa deportiva catalana y madrileña hemos efectuado un censo de ejemplos paralelo para cada fuente citada. Ello quiere decir que los titulares de la misma serie hablan de un mismo evento, que normalmente es un partido del Barça o del Madrid.

Apúntesequenuestrocorpusdereferencia, apartede sertemáticamente muy preciso, dado el carácter especial del presente estudio, cumple antes de todo con todos los requisitos teóricos de la constitución de bases de datos comparables. Recordemos brevemente los parámetros de los que se sirven los teóricos para diferenciar un conjunto accidental de textos y un corpus de índole científica: todos los textos han de tratar de la misma temática, pertenecer a un mismo género lingüístico o literario, haber sido publicados en un mismo periodo de tiempo, caracterizarse por un estilo semejante y seguir el mismo modo de transmisión (escrito, oral o digital) (cfr. Lewandowska-Tomaszczyk, 2005: 52 y ss.).

Nuestro corpus es de tipo continuo, lo que quiere decir que los titulares hablan de todos los partidos consecutivos que jugaron el Real Madrid y el Fútbol Club Barcelona, tanto en la liga española como en la competición europea, desde el 3 de febrero 2018 hasta el 13 de mayo 2018. En total se trata de 160 ejemplos de titulares recogidos en las cinco fuentes que a veces van acompañados tanto de otros titulares de un mismo ejemplar o de subtítulos que sirven de apoyo a nuestros comentarios. En algunas ocasiones, nos servimos de ejemplos sueltos recogidos fuera del corpus de referencia de base, que aprovechamos en otro trabajo (Bień, 2017).

\section{Análisis pragma-léxico de los titulares censados}

Huelga explicar que el trasfondo social y político es un factor que propicia el análisis de la prensa catalana y castellana. De hecho, es fácil observar que la eterna rivalidad entre el Barcelona y el Madrid se sale del

${ }^{1}$ Que se diferencia de <sports.pl>, página oficial digital del periódico deportivo polaco más importante, Przeglad Sportowy, y que tiene su versión en papel. 
simple marco deportivo, impactando las relaciones sociales y fomentando las tensiones políticas.

Los titulares pueden asumir dos funciones opuestas: destacar lo más relevante de la noticia, pero de igual modo pueden disminuir la importancia del éxito del equipo rival, amortiguar la responsabilidad de un equipo por una derrota o manchar explícitamente la reputación del campo rival. De hecho, como afirma Gómez Bueno, la intimidad y el honor de los actores de las noticias en la prensa deportiva están constantemente amenazados. Es más, según el autor citado, varios titulares (suponemos que también los textos enteros) violan literalmente todos los códigos éticos que regulan las cuestiones deontológicas en el periodismo local y europeo:

Hemos podido corroborar, con los ejemplos expuestos, que los diarios impresos catalanes, Sport y Mundo Deportivo, incumplen los siguientes artículos de los códigos deontológicos: el art. 8 del código de la FIP; el art 6 del código de la UNESCO; el art. 23 del Código Europeo de Deontología; el art. 9 del código del Colegio de Periodistas de Cataluña y el art. 4 del código de la FAPE. Estas normas sancionan el empleo del sensacionalismo cuando se producen difamaciones o intromisiones gratuitas en el honor y en la vida privada de los protagonistas (Gómez Bueno, 2014: 273).

Para dar una prueba material de su postura, el autor aludido cita algunos titulares perlas, publicadas en la versión en papel de Sport catalán:

El próximo verano el Madrid será campeón en... la prensa rosa (Sport, 2.03.11)

Irina Shayk tan repelente como Cristiano Ronaldo (Sport, 20.03.11)

A fin de llegar a algunas conclusiones pertinentes acerca del perfil discursivo dominante en los titulares que abarca nuestro corpus, los hemos repartido en dos grupos temáticos en los que se resumen los partidos del Madrid y los que relatan las actuaciones del Barça. A posteriori, ambos grupos fueron divididos entre titulares que relatan sucesos positivos y negativos para los protagonistas de la noticia. Los titulares censados han recibido tres posibles evaluaciones por nuestra parte, según si relatan los hechos de manera neutra, positiva o negativa. Se trata de un enfoque algo intuitivo ya que la valoración subjetiva de un mismo titular no se basa solamente en el sentido léxico propio de sus constituyentes, sino también en el sentido figurado que éstos cobran en función de las distintas circunstancias enunciativas o factores extralingüísticos ${ }^{2}$. La tabla que sigue resume los contenidos de todos los titulares analizados:

${ }^{2}$ Seguimos en alguna medida a Kajtok (2011: 130 y ss.) donde encontramos varias propuestas sobre cómo medir la evaluación subjetiva del contenido de los titulares. El lingüista polaco somete a análisis la actitud de los autores de las noticias hacia su contenido 
Tabla 1. Contenido temático (positivo / negativo) de los titulares deportivos analizados

\begin{tabular}{|c|c|c|c|c|c|c|c|}
\hline & & & as.com & marca.com & md.com & sport.es & sport.pl \\
\hline \multirow{3}{*}{$\mathbf{R M}$} & \multirow{3}{*}{$\begin{array}{l}\text { suceso } \\
\text { positivo (14 } \\
\text { casos) }\end{array}$} & + & 12 & 14 & 6 & 3 & 11 \\
\hline & & $=$ & 2 & 0 & 6 & 7 & 3 \\
\hline & & - & 0 & 0 & 2 & 4 & 0 \\
\hline \multirow{3}{*}{ RM } & \multirow{3}{*}{$\begin{array}{l}\text { suceso } \\
\text { negativo (4) }\end{array}$} & + & 0 & 1 & 0 & 0 & 0 \\
\hline & & $=$ & 2 & 3 & 0 & 0 & 0 \\
\hline & & - & 2 & 0 & 4 & 4 & 4 \\
\hline \multirow{3}{*}{ B } & \multirow{3}{*}{$\begin{array}{l}\text { suceso } \\
\text { positivo (8) }\end{array}$} & + & 4 & 6 & 7 & 6 & 6 \\
\hline & & $=$ & 3 & 2 & 1 & 2 & 2 \\
\hline & & - & 1 & 0 & 0 & 0 & 0 \\
\hline \multirow{3}{*}{ B } & \multirow{3}{*}{$\begin{array}{l}\text { suceso } \\
\text { negativo (6) }\end{array}$} & + & 2 & 0 & 2 & 2 & 0 \\
\hline & & $=$ & 2 & 3 & 2 & 2 & 4 \\
\hline & & - & 2 & 4 & 2 & 2 & 2 \\
\hline
\end{tabular}

presentación de los hechos (+ positiva; = neutra; - negativa); md: mundo deportivo.

Fuente: elaboración propia.

\section{Comentarios}

Los casos en los que todos los titulares de una misma serie contienen una valoración positiva de la actuación de uno de los dos equipos son muy poco representativos en nuestro corpus y se trata sobre todo de los eventos protagonizados por el Barça (subrayamos los elementos valorativos):

as.com: El Barça pasa el luto (Ejemplo 25; 14.04.18; Barça-Valencia 2-1)

marca.com: El Barça se levanta del golpe

sport.es: El Barça sabe sobrevivir y huele a campeón

en términos de polarización positiva, neutra o negativa, según el léxico que sirve para describir los hechos relatados. Los datos que aporta son de lo más interesantes: cuando la noticia habla de los deportistas, los titulares les describen de manera positiva, neutra o negativa en $38 \%$, 38\% y $24 \%$ de los casos, respectivamente; cuando los protagonistas del mensaje son personas anónimas, la repartición del léxico evaluativo es mucho más neutra: $16 \%, 62 \%$ y $22 \%$; en cambio, cuando la noticia está protagonizada por políticos, en la descripción prevalece la polaridad negativa: 19\%, 35\% y 46\% respectivamente. Su estudio se basa en 1000 titulares recogidos en la prensa sensacionalista polaca. 
md.com: El Barça se redime con una victoria de oro

sport.pl: Barcelona nie zachwyciła, ale pobiła rekord wszechczasów!

La derrota siempre da motivo de abusar lingüísticamente del campo adverso con algunos apelativos de intensidad bien seleccionados. Según hemos podido observar, es un fenómeno mucho más agresivo y mucho más frecuente en los dos periódicos catalanes sometidos al análisis:

as.com: Kepa dejó su tarjeta (Ejemplo 27; 18.04.18; RM-Athletic 1-1)

marca.com: Sólo CR7 puede con Kepa

sport.es: El Athletic frena a un Madrid impotente

md.com: Cristiano evita en el 87' la derrota del Madrid ante el Athletic

sport.pl: Real znów traci punkty. Gol Ronaldo w końcówce meczu

La falta de aprobación de los éxitos ajenos es flagrante en varios titulares de los medios catalanes, que lo expresan de manera implícita mediante una estratagema que consiste en evaluar el fondo de la noticia (mala actuación del contrincante del Madrid o un arbitraje discutible) en detrimento del hecho principal que es el éxito madridista. He aquí un par de ejemplos que resaltan este fenómeno:

as.com: Este sí es el Madrid (Ejemplo 5, RM-PSG 3-1; 14.02.18)

sport.es: Ni el PSG ni Unai Emery han aprendido nada

marca.com: El Rey conquista París (Ejemplo 16, PSG-RM 1-2; 6.03.18)

sport.es: La misma 'peli' de siempre

El caso más flagrante de alejamiento de la verdadera referencia factual es el titular de sport.es, publicado justo después de la victoria del Real Madrid en la final de la Champions contra el Liverpool:

marca.com: La 13 es de Bale (Ejemplo 32, RM-Liverpool 3-1; 26.05.18)

as.com: Eternamente campeón

md.com: Bale le da al Real Madrid su tercera Champions seguida

sport.es: BOMBA CRISTIANO: 'Fue muy bonito estar en el Real Madrid'

sport.pl: TEN FINAŁ ZAPAMIĘTAMY NA LATA! Kuriozalne błędy, piękne gole, dramat gwiazd

Mientras que lo notorio de la situación es innegable para toda la prensa mundial, el periódico catalán desvía la atención de sus lectores de lo estrictamente deportivo con una valoración peculiar de la actuación indecisa del jugador madrileño. Tan solo algún tiempo después aparece un titular de valor factual, que menosprecia, por otro lado, el éxito madridista (Karius le regala la decimotercera al Real Madrid). 


\section{A modo de conclusión}

Nuestro breve estudio de los titulares de la prensa deportiva en línea nos lleva a hacer algunas observaciones que en el futuro pueden cobrar más peso científico si están basadas en un corpus más extenso. Entre los medios digitales catalanes y los madrileños sometidos a análisis notamos diferencias sensibles en cuanto a la valoración positiva de los logros ajenos: mientras que interfaces como marca.com o as.com no se abstienen de hablar positivamente de los éxitos del club contrario, la prensa catalana desvía la atención del lector de los éxitos del Madrid con evaluaciones (normalmente negativas) a los hechos y personajes de segundo plano. Esta técnica puede volverse muy eficaz, sobre todo entre los lectores familiarizados con el 'conflicto' futbolístico existente entre ambos clubes. El único medio polaco que nos sirve de tertium comparationis conserva, en la mayoría de los casos, una postura de neutralidad proponiendo titulares motor muy extensos, centrados más en el aspecto informativo que expresivo. El alto grado de sensacionalismo de los medios catalanes digitales analizados aquí radica sin duda en uno de los fundamentos de la prensa deportiva, que se traduce en convertir al público en un concursante, el participante del dramatismo del evento exagerado hasta lo inusual (Domínguez Pérez, 2009).

\section{Bibliografía}

ALARCOS LLORACH, E. (1977). «El lenguaje de los titulares», en AA.VV, Lenguaje en periodismo escrito. Madrid: Juan March, 125-148.

BIEŃ, J. (2017). «Ambigüedad en la prensa tradicional y digital. Estudio de titulares en tres lenguas: español, francés y polaco», Itinerarios, 25, 147-166.

DOMÍNGUEZ PÉREZ, J. P. (2009). «Ensayo sobre la cuádruple espectacularidad del periodismo deportivo», Razón y Palabra, 69 (sin págs.) [en línea] <https:// dialnet.unirioja.es/ejemplar/234651>, fecha de consulta: 17 de septiembre 2018.

EL MUNDO (2002). Libro de estilo del diario 'el Mundo'. Madrid: Temas de hoy.

EL PAÍS (2014). Libro de estilo. Madrid: Aguilar.

FUENTE GONZÁLEZ, M. Á. (1991). «Introducción a los titulares de la prensa», Tabanque, 7, 159-181.

GÓMEZ BUENO, J. (2014). «Análisis ético de la prensa deportiva escrita en Cataluña, en el empleo de técnicas sensacionalistas», Razón y Palabra, 85, 256-280 [en línea] <www.revistarazonypalabra.org/index.php/ryp/article/view/429>, fecha de consulta: 16 de septiembre 2018. 
GOZALO GÓMEZ, P. (2004). «Los titulares de prensa en el aula de español lengua extranjera. Propuestas didácticas», en H. PERDIGUERO y A. ÁLVAREZ (eds.), Medios de comunicación y enseñanza del español como lengua extranjera. Burgos: Universidad de Burgos, 654-665.

GRIJELMO, Á. (2001). El estilo del periodista. Madrid: Taurus.

JORQUES, D. (2000). Discurso e información. Estructura de la prensa escrita. Cádiz: Universidad de Cádiz.

KAJTOK, W. (2011). «W świecie tabloidowych nagłówków. Ich retoryka oraz tworzony przez nie obraz rzeczywistości», Oblicza Komunikacji, 4, 119-138.

LEWANDOWSKA-TOMASZCZYK, B. (2005). Podstawy językoznawstwa korpusowego. Łódź: Wydawnictwo Uniwersytetu Łódzkiego.

NADAL PALAZÓN, J. (2008). «Verdades a medias: la nominalización deverbal en los titulares periodísticos», Comunicación y sociedad, 9, 175-190.

OLIVA MARAÑÓN, C. (2011). «Análisis léxico de los titulares de prensa en Internet», en F. VILCHES VIVANCOS (ed.), Un nuevo léxico en la red. Madrid: Dykinson, 53-69.

STEEL, B. (1971). «Los estilos funcionales y la enseñanza del idioma», Español Actual, 18, 9-18.

CORPUS: <marca.com; as.com>, <sport.es>, <mundodeportivo.com>, <sport.pl> (acceso: 3.02.2018-13.05.2018). 